\title{
EPSL
}

\section{Periodic behavior in lava dome eruptions}

\author{
A. Barmin ${ }^{a}$, O. Melnik ${ }^{a, b}$, R.S.J. Sparks ${ }^{b, *}$ \\ a Institute of Mechanics, Moscow State University, 1-Michurinskii prosp., Moscow 117192, Russia \\ b Centre for Geophysical and Environmental Flows, Department of Earth Sciences, University of Bristol, Wills Memorial Building, \\ Queen's Road, Bristol BS8 1RJ, UK
}

Received 16 September 2001; accepted 20 February 2002

\begin{abstract}
Lava dome eruptions commonly display fairly regular alternations between periods of high activity and periods of low or no activity. The time scale for these alternations is typically months to several years. Here we develop a generic model of magma discharge through a conduit from an open-system magma chamber with continuous replenishment. The model takes account of the principal controls on flow, namely the replenishment rate, magma chamber size, elastic deformation of the chamber walls, conduit resistance, and variations of magma viscosity, which are controlled by degassing during ascent and kinetics of crystallization. The analysis indicates a rich diversity of behavior with periodic patterns similar to those observed. Magma chamber size can be estimated from the period with longer periods implying larger chambers. Many features observed in volcanic eruptions such as alternations between periodic behaviors and continuous discharge, sharp changes in discharge rate, and transitions from effusive to catastrophic explosive eruption can be understood in terms of the non-linear dynamics of conduit flows from open-system magma chambers. The dynamics of lava dome growth at Mount St. Helens (1980-1987) and Santiaguito (1922-2000) was analyzed with the help of the model. The best-fit models give magma chamber volumes of $\sim 0.6 \mathrm{~km}^{3}$ for Mount St. Helens and $\sim 65 \mathrm{~km}^{3}$ for Santiaguito. The larger magma chamber volume is the major factor in explaining why Santiaguito is a long-lived eruption with a longer periodicity of pulsations in comparison with Mount St. Helens. (C) 2002 Elsevier Science B.V. All rights reserved.
\end{abstract}

Keywords: lava; shield volcanoes; eruptions; periodicity

\section{Introduction}

Several lava dome eruptions have been documented in detail over the last few decades. All

\footnotetext{
* Corresponding author. Tel.: +44-0117-954-5419; Fax: +44-0117-925-3385.

E-mail addresses: barmin@imec.msu.ru (A. Barmin), melnik@imec.msu.ru (O. Melnik), steve.sparks@bristol.ac.uk (R.S.J. Sparks).
}

of them show pulsations of magma discharge which are sometimes quite regular. Such volcanic systems can also display prolonged periods of steady discharge and sudden transitions between effusive and explosive activity. In the eruption of Mount St. Helens [1] in 1980-1986 more than 20 short episodes of dacite dome growth, lasting 2-7 days, alternated with longer periods of no growth. There were two sequences of periodic dome growth with an intervening episode of near continuous dome growth lasting 368 days. The San- 
tiaguito dacite dome, Guatemala, has been continuously active since 1922 . Dome growth is characterized by periods of $3-5 \mathrm{yr}$ of relatively high discharge rate alternating with periods of 3-11 yr of low discharge rate [2,3]. The 1991-1995 eruption of Mount Unzen involved two periods of high discharge rate separated by a period of low discharge of a few months in which activity almost ceased [4]. The Soufrière Hills volcano, Montserrat, has so far involved two major periods of dome growth (July 1995 to March 1998 and November 1999 to present) with a period of no growth of 20 months in between [5]. Shiveluch volcano, Kamchatka, has experienced short periods (a few months) of explosive eruptions and dome growth (1963-1964, 1971-1972, 1983-1984, 1993 and 2001) alternating with several years of dormancy [6]. Less detailed descriptions of many dome and lava eruptions suggest that such pulsatory and sometimes periodic activity is characteristic, but has remained unexplained.

We developed a model of conduit flow in lava dome eruptions from an open-system pressurized magma chamber. The model incorporates the kinetics of crystallization and rheological stiffening that accompanies degassing in ascending magma and takes account of the elastic deformation of the magma chamber walls. The results of the modelling provide a simple explanation of periodic behavior as a consequence of the non-linear dynamics of magmatic systems. The models are applied to interpretation of the lava dome eruptions on Mount St. Helens and Santiaguito.

\section{Model formulation}

There are large numbers of parameters that can influence volcanic activity. Alternative modelling strategies are either to produce complex numerical codes which try to incorporate all parameters or to make some simplifying assumptions so that a more tractable mathematical description can be developed which still captures the critical features of the physical system. The former approach is most valuable when a particular eruption is being modelled in great detail. For example in modelling the activity of the Soufrière Hills volcano,
Montserrat, Melnik and Sparks [7] parameterized the rheological properties of the andesite magma based on petrological and experimental data, and used eruption-specific parameters. However, such specific models are not generic and it is more difficult to explore how the main controls interact. Here we adopt the latter approach on the basis that patterns of pulsatory and periodic behavior are commonly observed and therefore the underlying causes are not likely to be dependent on the detailed choice of parameters. The aim of model formulation is thus to develop a mathematical description which retains key features of the physics, but is not so complex as to obscure how the major parameters interact.

The conceptual model is shown in Fig. 1. There is a magma chamber with elastic walls which is being fed at a constant influx rate from greater depth. During magma ascent gas exsolution and degassing-induced crystallization [8-10] occur due to the decrease in pressure. The rheological transition from relatively fluid magma to crystal-rich partially molten material can take place in the conduit due to these processes. There are very large changes of magma rheology for small changes of crystal content at crystallinities close to the formation of a touching framework $[11,12]$. The schematic viscosity profile along the conduit (thin curve in Fig. 1) shows a sharp increase in viscosity around a depth $x_{*}$ in the conduit where this rheological transition occurs. A key simplification here is to divide the magma into a lower zone of low viscosity, $\mu_{1}$, and an upper zone of high viscosity, $\mu_{2}$ (thick curve in Fig. 1). Whether the transition to high viscosity flow happens in the conduit or not depends critically on crystallization kinetics, and hence on magma ascent rate.

Conceptually the flow system can exist in two states: a state where the ascent is too fast for crystals to grow sufficiently to cross the rheological transition and a state where the ascent is slow enough that abundant crystals grow and the rheological transition is crossed in the conduit. In the first case magma ascends with a rate controlled by a relatively low viscosity, depending only on the concentration of dissolved gas. In the second case the upper conduit contains magma with orders of magnitude larger viscosity. Melnik and Sparks [7], 


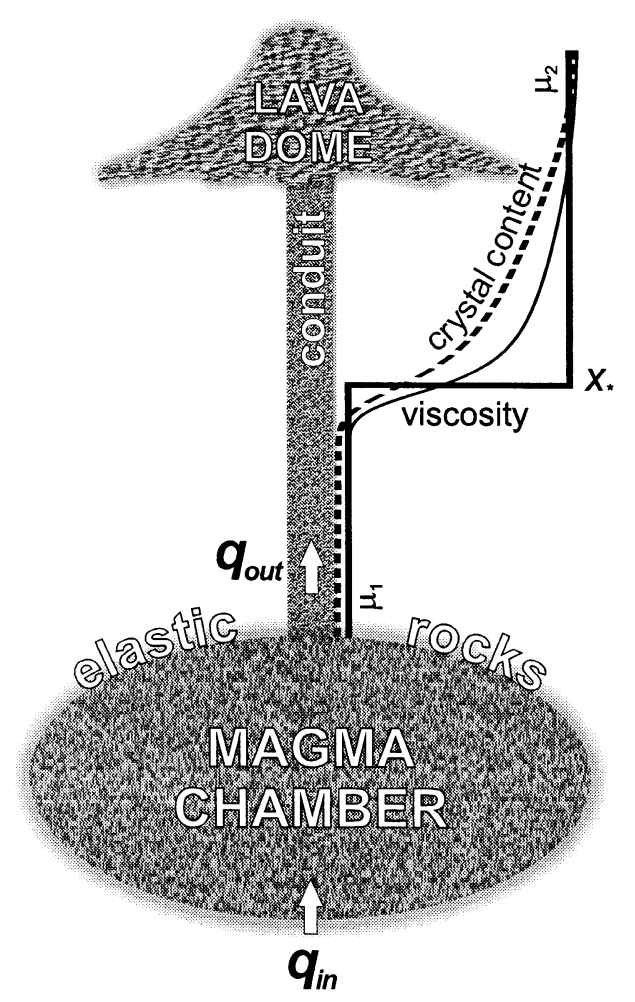

Fig. 1. A schematic view of the model volcanic system. Magma ascends at flux $q_{\text {out }}$ from a chamber recharged from below at a flux $q_{\text {in }}$ and connected with the growing lava dome by a cylindrical conduit. Flow in the dome is represented by a continuation of the conduit with extrusion of new lava at the summit of the dome. Schematic profiles of crystal content (dashed line), viscosity (light solid line) and the simplified viscosity profile (heavy solid line) are shown on the right. $x_{*}$ is the depth at which the magma reaches a critical crystal concentration and viscosity changes from $\mu_{1}$ to $\mu_{2}$.

using a quasi-static approach, showed that the non-linear dynamics of such a system could produce cyclic alternations of high and low discharge under some values of chamber pressure. Our study also complements the results of Whitehead and Helfrich [13], who found that cooling of rising magma could cause periodic behavior and demonstrated the phenomenon with simple laboratory experiments.

\section{Model description}

We make the following simplifications of a model of magma ascent during a lava dome eruption [7]: there are no density changes due to gas exsolution and crystal growth, the nucleation of crystals is instantaneous, crystal growth rate is constant, and the magma is a Newtonian liquid with a viscosity dependence on volume concentration of crystals as a step function. All symbols with units are defined in Table 1 . The system of equations in the unsteady $1 \mathrm{D}$ case with a constant cross-sectional area is as follows:

$$
\begin{aligned}
& \frac{\partial}{\partial t} \rho+\frac{\partial}{\partial x} \rho u=0 ; \frac{\partial}{\partial t} n+\frac{\partial}{\partial x} n u=0 ; \\
& \frac{\partial p}{\partial x}=-\rho g-\frac{32 \mu u}{\delta^{2}} ; \mu=\left\{\begin{array}{l}
\mu_{1}, \beta<\beta_{*} \\
\mu_{2}, \beta \geq \beta_{*}
\end{array}\right. \\
& \frac{\partial}{\partial t} \beta+u \frac{\partial \beta}{\partial x}=4 \pi n r^{2} \chi=(36 \pi n)^{1 / 3} \beta^{2 / 3} \chi
\end{aligned}
$$

Here $\rho$ is the density of magma, $u$ is the ascent velocity, $n$ is the number density of crystals per unit volume, $p$ is the pressure, $g$ is the gravity acceleration, $\delta$ is the conduit diameter, $\beta$ is the volume concentration of crystals, $\beta_{*}$ is a critical concentration of crystals above which the viscosity changes from $\mu_{1}$ to $\mu_{2}, r$ is the crystal radii, $\chi$ is the linear crystal growth rate, and $x$ is the vertical coordinate. The first two equations (Eq. 1a) represent conservation of mass and the number density of crystals, the second (Eq. 1b) is the momentum equation with negligible inertia, and the third (Eq. 1c) is the crystal growth equation with $\chi=$ constant, which is a reasonable first-order approximation $[8,14]$. We assume the following boundary conditions for the system Eqs. 1a,b,c:

$$
\begin{aligned}
& x=0: \frac{\mathrm{d} p_{\mathrm{ch}}}{\mathrm{d} t}=\frac{\gamma}{V_{\mathrm{ch}}}\left(q_{\text {in }}-q_{\text {out }}\right) ; \beta=\beta_{\mathrm{ch}} ; n=n_{\mathrm{ch}} \\
& x=l: p=0
\end{aligned}
$$

Here $\gamma$ is the rigidity of the wallrock of the magma chamber, $V_{\text {ch }}$ is the chamber volume, $\beta_{\mathrm{ch}}$ and $n_{\mathrm{ch}}$ are the crystal concentration and number density of crystals per unit volume in the chamber, $p_{\mathrm{ch}}$ is the pressure in the chamber, $l$ is the conduit length, $q_{\text {in }}$ is the flux into the chamber and $q_{\text {out }}=\pi \delta^{2} u / 4$ is the flux out of the 
Table 1

Notation and dimensionless parameters for the model

\begin{tabular}{|c|c|c|}
\hline $\begin{array}{l}\text { Parame- } \\
\text { ter }\end{array}$ & Units & Description \\
\hline \multicolumn{3}{|c|}{ Dimensional parameters } \\
\hline$g$ & $\mathrm{~m} / \mathrm{s}^{2}$ & acceleration due to the gravity \\
\hline$l$ & $\mathrm{~m}$ & conduit length \\
\hline$n$ & $1 / \mathrm{m}^{3}$ & number density of crystals \\
\hline$p$ & $\mathrm{~Pa}$ & pressure \\
\hline$p_{*}$ & $\mathrm{~Pa}$ & strength of chamber wallrocks \\
\hline$q$ & $\mathrm{~m}^{3} / \mathrm{s}$ & magma flux \\
\hline$q_{\text {in }}$ & $\mathrm{m}^{3} / \mathrm{s}$ & magma flux into the chamber \\
\hline$q_{\text {out }}$ & $\mathrm{m}^{3} / \mathrm{s}$ & magma flux out of the chamber \\
\hline$r$ & $\mathrm{~m}$ & crystal radii \\
\hline$t$ & $\mathrm{~s}$ & time \\
\hline$t_{*}$ & $\mathrm{~s}$ & characteristic time scale $\left(t_{*}=l / u_{*}\right)$ \\
\hline$V_{\text {ch }}$ & $\mathrm{m}^{3}$ & magma chamber volume \\
\hline$u$ & $\mathrm{~m} / \mathrm{s}$ & magma ascent velocity \\
\hline$u_{*}$ & $\mathrm{~m} / \mathrm{s}$ & characteristic velocity $\left(u_{*}=\rho g \delta^{2} / 32 \mu_{1}\right)$ \\
\hline$x_{*}$ & $\mathrm{~m}$ & level in the conduit where critical concentration of crystals is reached \\
\hline$x$ & $\mathrm{~m}$ & vertical coordinate \\
\hline$\beta$ & - & volume concentration of crystals \\
\hline$\beta_{*}$ & - & critical volume concentration of crystals \\
\hline$\varepsilon_{*}$ & $1 / \mathrm{s}$ & $\chi\left(n_{\mathrm{ch}}\right)^{1 / 3}-$ see Eq. 4 \\
\hline$\chi$ & $\mathrm{m} / \mathrm{s}$ & linear crystal growth rate \\
\hline$\delta$ & $\mathrm{m}$ & conduit diameter \\
\hline$\gamma$ & $\mathrm{Pa}$ & rigidity of chamber wallrocks \\
\hline$\mu$ & $\mathrm{Pa} \mathrm{s}$ & magma viscosity \\
\hline$\mu_{1}$ & $\mathrm{~Pa} \mathrm{~s}$ & magma viscosity below critical concentration of crystals $\left(\beta_{*}\right)$ \\
\hline$\mu_{2}$ & $\mathrm{~Pa} \mathrm{~s}$ & magma viscosity above critical concentration of crystals $\left(\beta_{*}\right)$ \\
\hline$\rho$ & $\mathrm{kg} / \mathrm{m}^{3}$ & density of magma \\
\hline 'ch' & - & corresponds to parameters values in the magma chamber \\
\hline \multicolumn{3}{|c|}{ Dimensionless variables } \\
\hline$P_{\mathrm{ch}}$ & $p_{\mathrm{ch}} /(\rho g l)$ & $\begin{array}{l}\text { chamber pressure }\left(P_{\mathrm{A}, \mathrm{B}, \mathrm{C}, \mathrm{D}}-\text { chamber pressure corresponding to transition }\right. \\
\text { points on Fig. } 2)\end{array}$ \\
\hline$t$ & $t / t_{*}$ & dimensionless time \\
\hline$T$ & $T / t_{*}$ & period of magma ascent velocity oscillations \\
\hline$U$ & $u / u_{*}$ & velocity $\left(U_{\mathrm{A}, \mathrm{B}, \mathrm{C}, \mathrm{D}}-\right.$ velocity corresponding to transition points on Fig. 2$)$ \\
\hline$X_{*}$ & $x_{*} / l$ & level, where critical concentration of crystals is reached $\left(\beta\left(X_{*}\right)=\beta_{*}\right)$ \\
\hline$\tau$ & $\int_{0}^{t^{\prime}} U(\lambda) \mathrm{d} \lambda$ & integration variable, proxy of time, $\lambda$-integration variable \\
\hline \multicolumn{3}{|c|}{ Dimensionless parameters } \\
\hline$\mu$ & $\mu_{2} / \mu_{1}$ & viscosity ratio \\
\hline$\kappa$ & $\left(\pi \delta^{2} \gamma\right) /\left(4 V_{\text {ch }} \rho g\right)$ & chamber pressure relaxation parameter \\
\hline$\psi$ & $\left(\left((4 / 3) \pi n_{0}\right)^{1 / 3} l \chi\right) /\left(u_{*}\left(\beta_{*}^{1 / 3}-\beta_{\mathrm{ch}}^{1 / 3}\right)\right)$ & dimensionless crystal growth rate \\
\hline$U_{\text {in }}$ & $\left(4 q_{\text {in }}\right) /\left(\pi \delta^{2} u_{*}\right)$ & dimensionless magma influx into the magma chamber \\
\hline
\end{tabular}

chamber into the conduit. Both $\beta_{\mathrm{ch}}$ and $n_{\mathrm{ch}}$ are assumed constant. We neglect the influence of variations of the height of the lava dome on the pressure at the top of the conduit, assuming that the pressure there is constant.

From the mass conservation equation $u=u(t)$ and $n=n_{\text {ch }}$ everywhere. To reformulate Eqs. 1a,b,c in dimensionless form the following scales are introduced: the length of the conduit $(l)$ for the vertical coordinate, the hydrostatic pressure drop $(\rho g l)$ for the pressure, the viscosity of low crystal content magma $\left(\mu_{1}\right)$ for the viscosities and the ratio between the hydrostatic pressure, the conduit resistance as a characteristic velocity $\left(u_{*}=\right.$ 
$\left.\rho g \delta^{2} / 32 \mu_{1}\right)$ and a characteristic time scale $\left(t_{*}=\right.$ $\left.l / u_{*}\right)$. We can specify four dimensionless combinations as follows:

$$
\begin{aligned}
& \mu=\frac{\mu_{2}}{\mu_{1}} ; \kappa=\frac{\pi \delta^{2} \gamma}{4 V_{\mathrm{ch}} \rho g} ; \\
& \psi=\frac{\left((4 / 3) \pi n_{\mathrm{ch}}\right)^{1 / 3} l \chi}{u_{*}\left(\beta_{*}^{1 / 3}-\beta_{\mathrm{ch}}^{1 / 3}\right)} ; \quad U_{\text {in }}=\frac{4 q_{\text {in }}}{\pi \delta^{2} u_{*}}
\end{aligned}
$$

These parameters will govern the eruption behavior. The parameter $\kappa$ is a measure of the storage capacity of the chamber and how quickly the chamber pressure changes in response to the relative values of the flux of magma into and out of the chamber. Large values of $\kappa$ correspond to small chambers with relatively wide conduits and small values of $\kappa$ correspond to large chamber volumes with relatively narrow conduits. The parameter $\psi$ reflects the importance of crystallization with $\psi$ increasing as the amount of crystallization increases during magma ascent. The parameter $U_{\text {in }}$ represents the intensity of magma influx into the chamber.

Omitting the details of the integration of equations we present the final set of ordinary differential equations in non-dimensional form:

$$
\begin{aligned}
& \frac{\mathrm{d} X_{*}(\tau)}{\mathrm{d} \tau}=\left\{\begin{array}{r}
1-U_{0} / U(\tau), \tau<X_{*} \\
1-U\left(\tau-X_{*}(\tau)\right) / U(\tau), \tau>X_{*}
\end{array}\right. \\
& \frac{\mathrm{d} P_{\mathrm{ch}}(\tau)}{\mathrm{d} \tau}=\kappa\left(\frac{U_{\mathrm{in}}}{U(\tau)}-1\right) \\
& P_{\mathrm{ch}}(\tau)= \\
& \left\{\begin{array}{r}
1+\left(\mu-(\mu-1) X_{*}(\tau)\right) U(\tau), X_{I N F}: S T A R T_{*} I N F: E N D<1 \\
1+U(\tau), X_{*}<1
\end{array}\right. \\
& \tau=\int_{0}^{t^{\prime}} U(\lambda) \mathrm{d} \lambda
\end{aligned}
$$

Here $U_{0}=U(\tau=0)$ is the initial magma ascent velocity, $\tau$ is an independent variable, the proxy of the time defined by Eq. $2 \mathrm{~d}, X_{*}(\tau)$ represents the level in the conduit where the critical volume con- centration of crystals is reached, $t^{\prime}$ is dimensionless time $\left(t^{\prime}=t / t_{*}\right)$, and $\lambda$ is an integration variable. System Eqs. 2a-d consists of two ordinary differential equations (Eqs. 2a,b), one of which (Eq. 2a) is complicated by a 'memory' effect, and one finite relation (Eq. 2c). We use the steady-state solution as an initial condition for the system. The initial chamber pressure $P_{\mathrm{ch}}(0)$ is calculated from Eq. 2c with $U(0)=U_{0}$ and $X_{*}(0)=U_{0} / \psi$. Two different cases are considered: $X_{*}<1$ when the critical concentration of crystals is reached in the conduit, and $X_{*}>1$ when the critical concentration of crystals is not reached and thus the viscosity in the conduit is approximated as constant. The equations are solved by means of a variable-step size, variable-order backward differentiation method, suitable for stiff problems [15]. To compute $V\left(\tau-X_{*}\right)$ the velocity is stored in an array and approximated by means of a third-order Legendre polynomial using the nearest points.

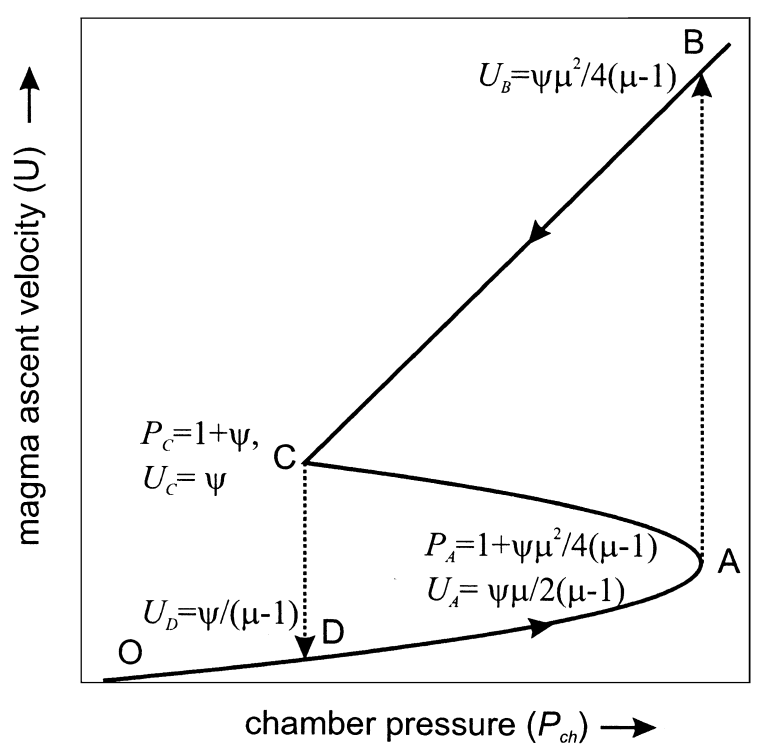

Fig. 2. The general steady-state solution and possible quasistatic evolution of an eruption. Coordinates of transition points are shown. Note that the magma ascent velocity and magma chamber pressure are plotted in their non-dimensional form (see Table 1). 


\section{Results of calculations}

The general steady-state solution for magma ascent velocity variations with chamber pressure is shown in Fig. 2 for $\mu>2$. This solution is obtained by the substitution $X_{*}=U / \psi$ into Eq. 2c. Solutions at high magma ascent velocities result in a straight line (CB), which is the same as for the classical Pouiseille solution for a fluid with constant viscosity. At low ascent velocities there is a parabolic relationship (OAC) between chamber pressure and ascent velocity. A transition between the lower $(\mathrm{OA})$ and the intermediate $(\mathrm{AC})$ regimes occurs at point $\mathrm{A}$ for $P_{\mathrm{A}}=1+\psi \mu^{2} / 4(\mu-1)$ and $U_{\mathrm{A}}=\psi \mu / 2(\mu-1)$. The transition to the upper regime $(\mathrm{BC})$ corresponds to the point $\mathrm{C}$ with $P_{\mathrm{C}}=1+\psi$ and $U_{\mathrm{C}}=\psi$. A key feature of the steady-state solution is that, for a fixed chamber pressure, it is possible to have three different magma ascent velocities. The existence of multiple regimes is a common characteristic of volcanic flow systems, as was first recognized by Slezin [16] and has been considered subsequently in several studies $[7,13,17-19]$. We note that for $\mu=1$ only the branch $\mathrm{CB}$ exists and for $1<\mu \leq 2$ there is a smooth transition between the lower branch
(ODA) and the upper branch (CB) and multiple steady-state regimes do not exist.

We first consider the case where chamber pressure changes quasi-statically and the value of $U_{\text {in }}$ is between $U_{\mathrm{A}}$ and $U_{\mathrm{C}}$. Starting at point $\mathrm{O}$ (Fig. 2) the chamber pressure increases, because the influx into the chamber is higher than the outflux. At the point $\mathrm{A}$ further increase in pressure is not possible and the system must change to point $\mathrm{B}$ where the outflux of magma is larger than the influx. The chamber pressure and ascent velocity decrease along $\mathrm{BC}$ until the point $\mathrm{C}$ is reached and the system must change to point $\mathrm{D}$. The cycle $\mathrm{DABC}$ then repeats itself. Provided the chamber continues to be supplied at the same constant rate repetition of this cycle results in periodic behavior. The transitions $\mathrm{AB}$ and $\mathrm{CD}$ in a cycle must involve unsteady flow.

Some initial comments can be made about the controls on periodic behavior based on the steady-state solution. Increase of the viscosity ratio will increase the amplitude of the velocity change for the unsteady jumps $A B$ and $C D$. The amplitude of a cycle, represented as $U_{\mathrm{B}} / U_{\mathrm{D}}$, also increases as the viscosity ratio increases. The position of point $\mathrm{C}$ depends only on the crystal

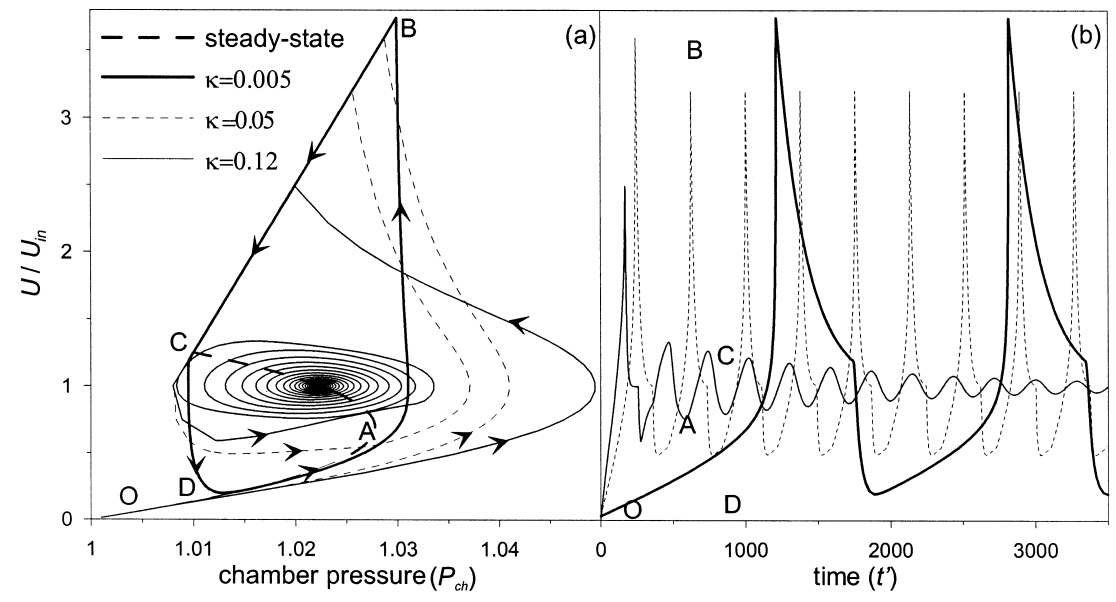

Fig. 3. Transient behavior of an eruption. The long-dashed line shows the steady-state solution for values of governing parameters: $\mu=10, \psi=10^{-2}, U_{\text {in }}=8 \times 10^{-3}$. Note that in the diagram the steady-state solution follows the path DACB and is the same as in Fig. 2. Three curves for unsteady flow behavior are shown for different values of $\kappa$. (a) shows the relation between ascent velocity and chamber pressure, (b) the variation of the ascent velocity with time. Note that $U / U_{\text {in }}=1$ corresponds to an exact balance of magma influx into the chamber and outflux along the conduit. All variables are non-dimensional. 


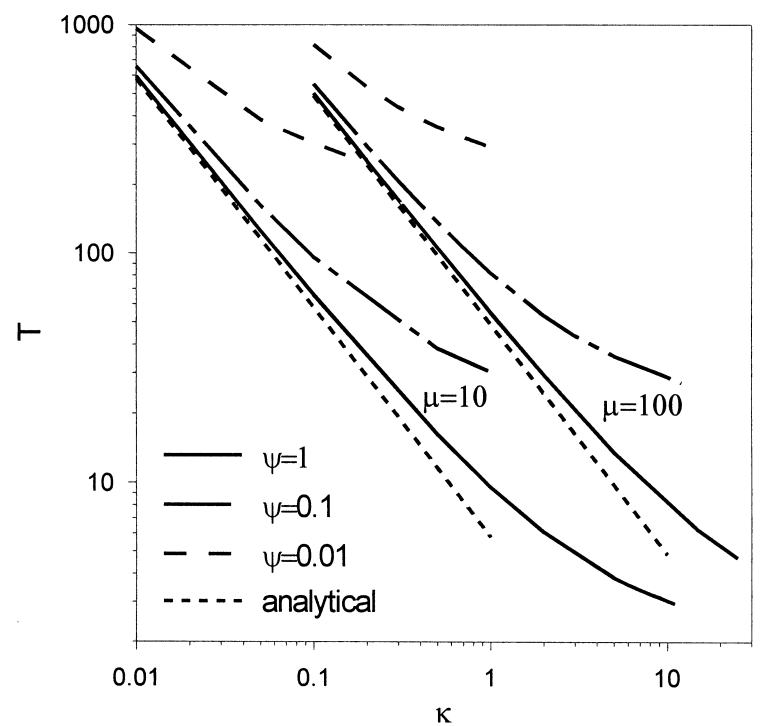

Fig. 4. The dependence of the period of oscillation, $T$, on the governing parameters: $\kappa$ depends on the chamber volume, $\psi$ depends on the crystal growth rate and $\mu$ is the viscosity ratio. An analytical solution is shown for $\kappa \rightarrow 0$ (dashed line).

growth parameter $\psi$. The maximum chamber overpressure (the difference between chamber pressure and lithostatic pressure) during a cycle is equal to $\Delta P_{\mathrm{A}}=P_{\mathrm{A}}-1=\psi \mu^{2} / 4(\mu-1)$. The maximum possible overpressures cannot exceed the typical strength limits of the surrounding rocks $p_{*}(\sim 20 \mathrm{MPa})$ [20]. This results in limits on the possible variations of parameters, so that $\Delta P_{\mathrm{A}}<p_{*} / \rho g l$.

Of more general interest is to consider unsteady flow behavior. We assume that the initial distribution of parameters in the conduit corresponds to the steady-state solution of system Eqs. 2a-d with the initial magma ascent velocity, $U_{0}$, being in the lowest regime. The behavior of an eruption with time depends strongly on the value of $U_{\text {in }}$. If $U_{\text {in }}$ corresponds to the upper or the lower branch of the steady-state solution the eruption stabilizes with time with $U=U_{\text {in }}$ and $\mathrm{d} P_{\mathrm{ch}} / \mathrm{d} \tau=0$. However, if $U_{\text {in }}$ corresponds to the intermediate branch of the steady-state solution with $U_{\text {in }}$ between $U_{\mathrm{A}}$ and $U_{\mathrm{C}}$ than periodic behavior is possible. Fig. 3 shows three scenarios of eruptions for different values of $\kappa$ for this case. When $\kappa$ is large $(\kappa=0.12)$ the eruption stabilizes with time. In con- trast, undamped periodic oscillations occur for values of $\kappa$ smaller than some critical value. For small values of $\kappa(\kappa=0.005)$ the transient solution almost exactly follows the steady-state solution with unsteady transitions between the regimes. The maximum ascent velocity during the cycle is close to $U_{\mathrm{B}}$, the minimum is close to $U_{\mathrm{D}}$ and the average velocity is equal to $U_{\text {in }}$. For larger values of $\kappa(\kappa=0.05)$ the maximum value of the ascent velocity is smaller, because the chamber pressure decreases during the transition from the lower to the upper regime. The period of pulsations increases as the value of $\kappa$ decreases (Fig. 3), corresponding to an increase in magma chamber size, if all other parameters defining $\kappa$ are held constant.

Fig. 4 shows the dependence of the period of the pulsations on the governing parameters. We chose the value of $U_{\text {in }}$ to be exactly in the middle of the intermediate regime of the steady-state solution $\left(U_{\mathrm{in}}=\left(U_{\mathrm{A}}+U_{\mathrm{C}}\right) / 2\right)$. The period of oscillations is a weak function of $U_{\text {in }}$ except when $U_{\text {in }}$ is near to transition points to other regimes where the period increases slightly. On a log-log scale the dependence of the period on $\kappa$ is linear for small values of $\kappa$, which means that the dependence is a power law with an exponent which depends on $\psi$ and $\mu$ and is in the range -0.95 to -0.55 . For larger values of $\kappa$ near the transition to the stabilization of eruption, the dependence of the period on $\kappa$ is weaker. In Fig. 4 the periodic behavior disappears and stable flow conditions arise at the right-hand end of the curves. The transition to stabilization occurs for smaller values of $\kappa$ when the viscosity ratio or crystal growth parameters are smaller.

For very small values of $\kappa$ the relation between the period of oscillations and the governing parameters can be obtained analytically. The steadystate relation between the critical level and the velocity $\left(x_{*}=V / \psi\right)$ remains satisfied with an accuracy of $\kappa^{2}$. Integration of Eqs. $2 b$ and $c$ with this assumption leads to:

$$
\begin{aligned}
T & =\frac{\mu}{\kappa U_{\mathrm{A}}}\left(U_{\mathrm{A}}-U_{\mathrm{D}}+\left(1-\frac{U_{\text {in }}}{U_{\mathrm{A}}}\right) \ln \left(\frac{U_{\text {in }}-U_{\mathrm{D}}}{U_{\text {in }}-U_{\mathrm{A}}}\right)\right)+ \\
& \frac{1}{\kappa} \ln \left(\frac{U_{\mathrm{B}}-U_{\text {in }}}{U_{\mathrm{C}}-U_{\text {in }}}\right)
\end{aligned}
$$


This equation can be simplified for the case when $U_{\text {in }}=\left(U_{\mathrm{A}}+U_{\mathrm{C}}\right) / 2$ :

$T=\frac{\mu-2}{\kappa}(\ln (\sqrt{3})+1)+\frac{\ln (\mu-1)}{\kappa}$

Values of the period are calculated from Eq. 3 and do not depend on $\psi$ and are also shown in Fig. 4 (short-dashed lines). As $\kappa \rightarrow 0$ these values get closer to those obtained from the system Eqs. $2 \mathrm{a}-\mathrm{d}$. Based on Eq. 3 the magma chamber size can be estimated if the period of oscillations is known and there are independent constraints on the conduit diameter and other parameters of the system.

\section{Case studies}

Now we apply the model to two well-documented eruptions: the growth of lava domes on Mount St. Helens (1980-1986) and on Santiaguito (1922-present). Our objective here is to establish that the model can reproduce the periodic behaviors observed at these two volcanoes. Estimates can be obtained for most of the system parameters. However, magma chamber size is not well constrained and so the model can be used to make inferences on relative chamber size. Given the uncertainties in the parameter values and the simplifications in the model development the approach can be characterized as mimicry. Adjustments in some parameters were made to achieve best fits with observations, but the particular best fits are not unique.

For Mount St. Helens our model is based on data presented by Swanson and Holcomb [1]. Three phases of activity can be distinguished during the period of dome growth. The first phase consists of nine pulses of activity with average peak discharge rates $\sim 12 \mathrm{~m}^{3} / \mathrm{s}$ during 19811982. Each pulse lasted from 2 to 7 days (with a mean value of 4 days) with the average period between the pulses being 74 days and the average discharge rate during this phase being $q_{1} \sim 0.67$ $\mathrm{m}^{3} / \mathrm{s}$. The second phase is represented by continuous dome growth and lasted more than a year (368 days) with a mean discharge rate of $q_{2} \sim 0.48$ $\mathrm{m}^{3} / \mathrm{s}$. During the last phase there were five epi- sodes of dome growth with peak discharge rates up to $\sim 15 \mathrm{~m}^{3} / \mathrm{s}$, an average period of pulsation of $\sim 230$ days and a mean discharge rate of $q_{3} \sim 0.23 \mathrm{~m}^{3} / \mathrm{s}$.

The presence of pulsations during the first phase and absence of pulsations for the second phase constrains values of non-dimensional parameters in the model system. If the influxes in these two periods are defined as $U(\mathrm{I})_{\text {in }}$ and $U(\mathrm{II})_{\text {in }}$ respectively then $\psi>U(\mathrm{I})_{\text {in }}>\psi / 2>U(\mathrm{II})_{\text {in }}$. This relationship can be simplified using the definitions of dimensionless parameters:

$\left(\frac{6}{\pi^{2}}\right) 1 / 3 \frac{q_{\mathrm{in}}^{2}\left(\beta_{*}^{1 / 3}-\beta_{\mathrm{ch}}^{1 / 3}\right)}{l \delta^{2}}<\varepsilon<$

$$
\left(\frac{6}{\pi^{2}}\right) 1 / 3 \frac{q_{\mathrm{in}}^{1}\left(\beta_{*}^{1 / 3}-\beta_{\mathrm{ch}}^{1 / 3}\right)}{l \delta^{2}} ; \varepsilon=\chi n_{\mathrm{ch}}^{1 / 3}
$$

Some parameters in Eq. 4 can be estimated independently. Estimates of conduit diameter $\delta$ of $20 \pm 5 \mathrm{~m}$ have been made by observations [1] and indirectly from magma ascent velocities estimated from amphibole reaction rims [21]. A chamber depth of $7.2 \mathrm{~km}$ was estimated by Pallister [22]. We take a nucleation density of $10^{14} \mathrm{~m}^{-3}$ to be consistent with observations of microphenocrysts abundance by Cashman and Blundy [8] on samples of lava and ejecta from the 1980-1986 period of lava dome growth. Assuming $l=7.2 \mathrm{~km}$, $\beta_{\mathrm{ch}}=0.3, \beta_{*}=0.7, q_{1}=0.67 \mathrm{~m}^{3} / \mathrm{s}, \quad q_{2}=0.48 \mathrm{~m}^{3} / \mathrm{s}$ and $\delta=18 \mathrm{~m}$ we obtain $4 \times 10^{-7}<\varepsilon<7.1 \times 10^{-8}$ and for $n_{\mathrm{ch}}=10^{14} \mathrm{~m}^{-3}$ the inferred crystal growth rates are in the range $1.5-2.1 \times 10^{-12} \mathrm{~m} / \mathrm{s}$. The choice of particular dimensionless parameters is not unique and can be narrowed if more information on the physical properties of the volcanic system is available.

The viscosity of magma with lower crystal content $\left(\mu_{1}\right)$ can be estimated using formulas [23] for the melt viscosity as a function of melt composition, temperature and water content, and empirical relations to account for crystal content $[11,12]$. A rhyolitic melt composition is used from [8] at a temperature of $900^{\circ} \mathrm{C}$. For the magma chamber (5 wt $\% \mathrm{H}_{2} \mathrm{O}, 30 \%$ crystals) the viscosity is estimated as $6.4 \times 10^{4} \mathrm{~Pa} \mathrm{~s}$, whereas in the vicinity of the critical level $X_{*}\left(2 \mathrm{wt} \% \mathrm{H}_{2} \mathrm{O}, 50 \%\right.$ crystals $)$ 

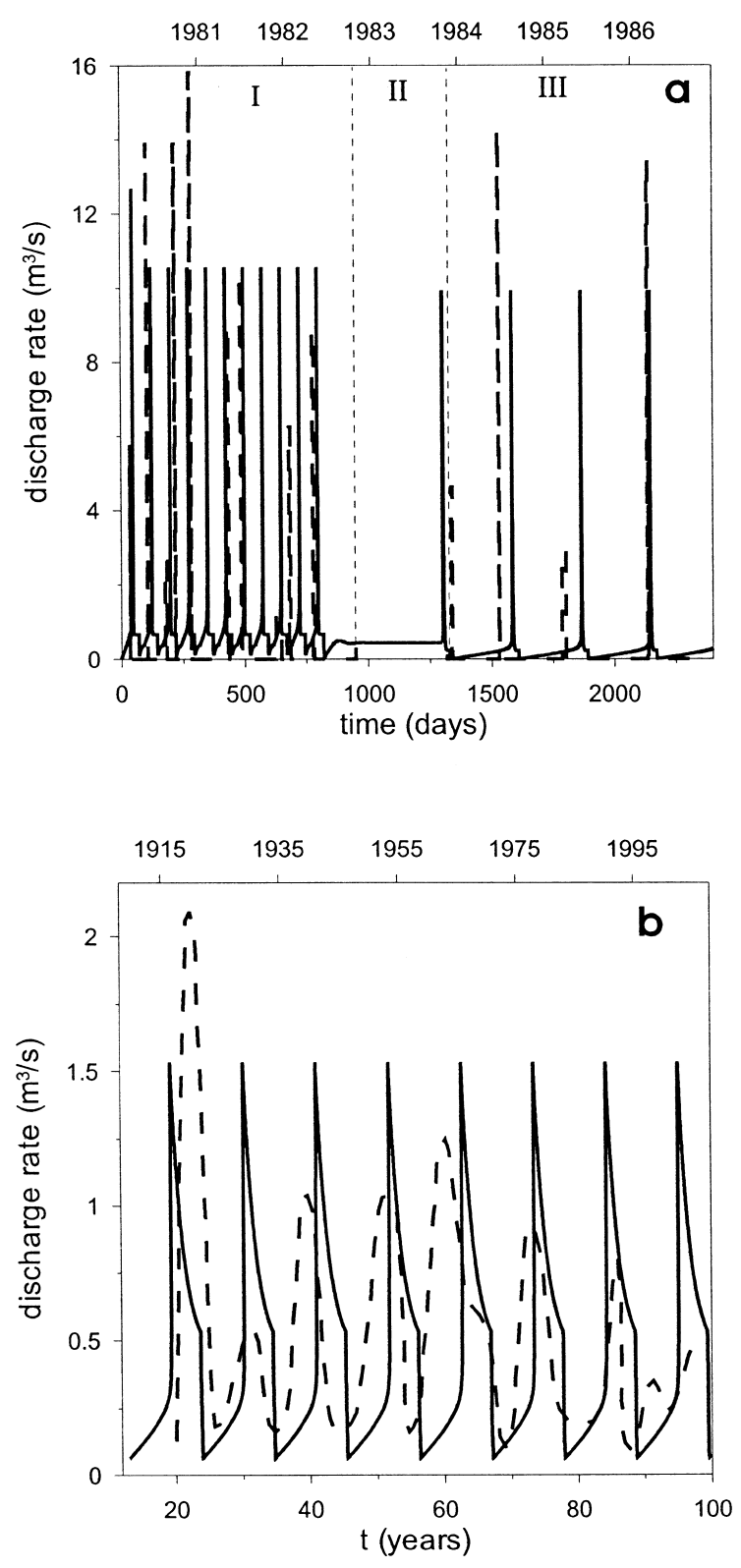

Fig. 5. Discharge rate versus time for (a) dome growth Mount St. Helens (1980-1986) and (b) Santiaguito (19222000). Dashed curves are the observed fluctuations in discharge rate and solid lines are the best-fit model simulations. Parameters used for these simulations are listed in Table 2.

the viscosity is $1.7 \times 10^{7} \mathrm{~Pa}$ s. The average value for $\mu_{1}$ should lie between those values, more likely nearer to the chamber value. We choose for an average viscosity of $6.4 \times 10^{5} \mathrm{~Pa} \mathrm{~s}, 10$ times higher than chamber viscosity. To provide a preliminary estimate of viscosity in the upper part of the conduit we can use the steady-state solution. The ratio of $U_{\mathrm{B}} / U_{\text {in }}=\mu^{2} /(3 \mu-2)=17.9$ was estimated, using a value of $\sim 12 \mathrm{~m}^{3} / \mathrm{s}$ as the peak discharge rate averaged over nine pulses and a mean discharge rate for this phase of $0.67 \mathrm{~m}^{3} / \mathrm{s}$. Thus we obtain $\mu=52.7$ as an initial estimate. The parameter $\mu$ was then varied during the calculations to obtain optimum agreement with the observations. In the unsteady case the ratio $U_{\mathrm{B}} / U_{\text {in }}$ is smaller than for the steady-state solution, because the chamber pressure decreases during the transition from the lower to the upper regime (Fig. 3a), and consequently the value of $U_{\mathrm{B}}$ is smaller than for the steady-state case.

Using the values discussed above we fix $\psi=9 \times 10^{-3}$ and $U_{\text {in }}=6.8 \times 10^{-3}$ and $4.8 \times 10^{-3}$ for the first and the second phases of the eruption respectively. We then vary parameters $\mu$ and $\kappa$ and made many runs of the code to obtain the best fit for the observed data. The best-fit model for the eruption is presented in Fig. 5a, with the parameters used for the simulation summarized in Table 2. For the third phase of the eruption the parameters of the system were changed, so that $U_{\text {in }}$ corresponds to the intermediate regime once again and periodic behavior occurs. The chamber volume, conduit length, chamber and critical crystal content are assumed to have remained the

Table 2

Parameters used for calculations for Mount St. Helens and Santiaguito lava dome eruptions

\begin{tabular}{lll}
\hline Parameter & Mount St. Helens & Santiaguito \\
\hline$\rho$ & $2500 \mathrm{~kg} / \mathrm{m}^{3}$ & $2500 \mathrm{~kg} / \mathrm{m}^{3}$ \\
$L$ & $7200 \mathrm{~m}$ & $5000 \mathrm{~m}$ \\
$D$ & $18\left(12^{\mathrm{a}}\right) \mathrm{m}$ & $20 \mathrm{~m}$ \\
$V_{\mathrm{ch}}$ & $0.56 \mathrm{~km}^{3}$ & $65 \mathrm{~km}^{3}$ \\
$\gamma$ & $3 \times 10^{10} \mathrm{~Pa}$ & $10^{10} \mathrm{~Pa}$ \\
$n_{\mathrm{ch}}$ & $10^{14} \mathrm{~m}^{-3}$ & $10^{14} \mathrm{~m}^{-3}$ \\
$U$ & $1.5 \times 10^{-12} \mathrm{~m} / \mathrm{s}$ & $10^{-12} \mathrm{~m} / \mathrm{s}$ \\
$\mu_{1}$ & $6.4 \times 10^{5} \mathrm{~Pa}$ & $6.4 \times 10^{6} \mathrm{~Pa}$ \\
$\mu$ & $80\left(110^{\mathrm{a}}\right)$ & 12 \\
$\beta_{\mathrm{ch}}$ & 0.3 & 0.3 \\
$\beta_{*}$ & 0.7 & 0.7 \\
\hline
\end{tabular}

a Parameters for the third period of the Mount St. Helens eruption are in parentheses. 
same in the third phase. The mean discharge rate of $0.23 \mathrm{~m}^{3} / \mathrm{s}$ is assumed to correspond to the influx into the chamber. With these fixed properties of the system one can show that the relation $\delta^{2}<$ const $/ \varepsilon$ must be satisfied for periodic behavior. This condition can be satisfied by a decrease in the conduit diameter or a decrease in the crystal growth rate or the number density of crystals. A decrease in the conduit diameter could be a consequence of magma crystallization on the conduit walls. For all other parameters being fixed the required change in diameter is from 18 to 12 $\mathrm{m}$. Alternatively a decrease in the crystal growth rate or the number density of crystals could reflect observed changes in the chemical composition of the magma in the third phase [1], noting that crystallization kinetics can be sensitive to melt composition.

Since 1922, extrusion at Santiaguito has been cyclic [2]. Each cycle begins with a 3-6-yr-long high $\left(0.5-2.1 \mathrm{~m}^{3} \mathrm{~s}^{-1}\right)$ discharge rate phase followed by a longer (3-11-yr-long) low $\left(\leq 0.2 \mathrm{~m}^{3}\right.$ $\mathrm{s}^{-1}$ ) discharge rate phase. The eighth cycle began in 1996 and was still in its high discharge rate phase during January 2000. The time-averaged discharge rate was almost constant at $\sim 0.44 \mathrm{~m}^{3}$ $\mathrm{s}^{-1}$ until 2000. The first peak in discharge rate had a value $>2 \mathrm{~m}^{3} / \mathrm{s}$, whereas the second peak had a much smaller value. Later peaks show an increase in discharge rate until 1960 (Fig. 5b, dashed line). Later on the duration of the low discharge rate phase increased, the peak discharge and the time-averaged discharge rates for each cycle decreased, and the difference between discharge rates during the high and low discharge rate phases of each cycle decreased.

A similar approach was used for the Santiaguito eruption. Our best-fit model is shown in Fig. 5 and the parameter estimates are listed in Table 2. The model captures the main features of the eruption, including the period of pulsations, the ratio between low and high discharge rates and the range of observed discharge rates. We cannot reproduce the decrease in the amplitude of pulsations within the framework of the model using fixed parameter values. Possible explanations are: a decrease in the magma viscosity $\mu_{1}$ as a consequence of the observed change in chemical composition of magma [24] leads to increase in characteristic velocity $u_{*}$, and, therefore, in a decrease in $U_{\text {in }}$. Alternatively changes in conduit diameter, magma chamber crystal content or magma influx intensity changes the steady-state solution in such a way that $U_{\text {in }}$ shifts to the lower or upper branches.

Our theory provides a potential method to estimate chamber volumes, because the period is most sensitive to the parameter $\kappa$, which is a strong function of chamber size. Magma chambers can be envisaged as capacitors, which can store magma in proportion to their volume in the quiet periods between pronounced pulses of magma discharge. For Mount St. Helens our estimate of the chamber size $\left(\sim 0.6 \mathrm{~km}^{3}\right)$ is comparable with the total erupted volume in the entire eruption and consistent with the lack of geophysical imaging of a large magma body. Santiaguito volcano erupted more than $10 \mathrm{~km}^{3}$ in the 1902 explosive eruption [25] and more than $1 \mathrm{~km}^{3}$ of lava domes since 1922. The best-fit model estimate of a large $\left(65 \mathrm{~km}^{3}\right)$ chamber is consistent with much larger eruption volumes, long periods, and longevity of the eruption in comparison to Mount St. Helens.

\section{Discussion}

A transient magma ascent model which accounts for crystallization in ascending magma and rheological transition during ascent has been developed. The governing partial differential equations were reduced to a system of ordinary differential equations, which allowed us to use a fast and accurately controlled computation algorithm. The steady-state solution for this system for fixed chamber pressure is not unique. Up to three steady-state regimes with magma ascent velocity differences of several orders of magnitude can appear at a fixed magma chamber pressure. A transition between the steady-state solutions can cause oscillatory variations of magma ascent rate with time. The period of oscillations depends on the size of magma chamber and other controlling parameters, notably magma influx rate and conduit diameter. 
For two case studies of dome eruptions at Mount St. Helens and Santiaguito the variations in discharge rates were successfully mimicked using observations and model-independent estimates of the main physical parameters. The values of parameters that are impossible to measure directly were also estimated using the model. However, the model is not fully quantitative. Some of governing parameters, such as those associated with crystallization rates and viscosity variations are not well constrained. Further, the model makes several simplifications which may affect the details of results. The model, for example, simplifies viscosity variations, does not consider the effect of variations of the dome height on pressure, assumes a constant magma density, and neglects complications due to lateral gradients of properties across the conduit. These and other complications would need to be incorporated into a model to interpret the patterns of lava dome eruptions more quantitatively and may change the values of parameters that give the best fits for the observed data.

For example, dome growth and destruction cause changes in pressure and hence eruption rate because they act to change the driving pressure for the flow [26]. However, in the case of Mount St. Helens the influence of the dome height variation on discharge rate is not the main factor controlling periodic behavior. Onset of each pulse involved ground deformation prior to renewed dome growth [1]. So the transition between no magma discharge and high magma discharge rate cannot be related to changes in dome height. Dome growth could contribute to ending a period of high discharge rate and would reduce the time of high discharge rate compared to model predictions. Explosive eruptions could also change the conditions. In Mount St. Helens some of early pulses of high discharge in the first phase involved explosive activity, which effectively increases discharge rate by shortening the conduit length and perhaps removing high viscosity degassed magma from the dome and upper conduit. Many of the pulsations at Mount St. Helens, however, did not involve explosive activity. Thus this mechanism cannot be the primary cause of periodicity, although it can clearly have a signifi- cant influence on the amplitude and duration of a pulse.

The alternative mechanism of pulsatory behavior proposed in [13] based on the variation of the temperature and, therefore, the viscosity in ascending magma is not applicable to lava dome eruptions. The model of Whitehead and Helfrich assumes the wall temperature to be time independent, and this feature is important for causing periodicity by cooling mechanism. However, in volcanic conduits during long-lived eruptions the thermal profiles mature and overall heat flux from ascending magma decreases. The thermal model of [13] may be more relevant to dyke injections into the cold media and to relatively short-lived eruptions.

Our study is part of a growing body of theory which can account for periodic and pulsatory behavior at volcanoes as a consequence of non-linear dynamics. Magma discharge rate can show very large and rapid changes because conduit flows can commonly be highly unstable to small changes of the parameters that govern flow, such as chamber pressure, gas content, magma rheology, density, conduit diameter and recharge rate of the chamber. A number of studies [7,13,1719,27], starting with Slezin [16], has shown how gas exsolution and gas escape can create multiple steady-state regimes and critical points where flow rate has to jump from low to high discharge rates and vice versa. These models predict abrupt transitions between explosive and effusive activity, as is commonly observed. Our work here and in Melnik and Sparks [7] adds to this theory by showing that pulsatory and periodic behavior can occur in extrusive eruptions related to rheological stiffening of degassing and crystallizing magma.

Model development so far has involved making some simplifications and approximations partly to elucidate underlying principles and partly because of uncertainties in material properties. Future model development can be expected to introduce more complex and realistic laws for kinetics of gas exsolution, crystal nucleation and growth, magma and wallrock rheology and time-dependent heat transfer between magma and conduit walls. New more complex patterns of behavior can be antici- 
pated and such models may allow quantitative estimates of important parameters such as magma chamber size.

\section{Acknowledgements}

The research was supported by NERC grant GR3/13020, by a NERC Fellowship to R.S.J.S., by RFBR (02-01-00067, Russia) and EC (MULTIMO). We thank Bill Rose and Jon Blundy for discussions related to the Santiaguito and Mount St. Helens eruptions. Reviews of the manuscript by Claude Jaupart, Bill Rose and Lionel Wilson were very helpful.[BW]

\section{References}

[1] D.A. Swanson, R.T. Holcomb, Regularities in growth of the Mount St. Helens dacite dome 1980-1986, in: J.H. Fink (Ed.), Lava Flows and Domes; Emplacement Mechanisms and Hazard Implications, Springer, Berlin, 1990, pp. 3-24.

[2] W.I. Rose, Pattern and mechanism of volcanic activity at the Santiaguito volcanic dome, Guatemala, Bull. Volcanol. 36 (1972) 73-94.

[3] W.I. Rose, Volcanic activity at Santiaguito volcano, 1976-1984, Geol. Soc. Am. 212 (1987) 17-27.

[4] S. Nakada, H. Shimizu, K. Ohta, Overview of the 19901995 eruption at Unzen Volcano, J. Volcanol. Geotherm. Res. 89 (1999) 1-22.

[5] R.S.J. Sparks, S.R. Young, The eruption of Soufrière Hills Volcano, Montserrat: overview of scientific results, in: T.H. Druitt, B.P. Kokelaar (Eds.), The Eruption of Soufrière Hills Volcano, Montserrat, from 1995 to 1999, Memoir, Geological Society, London, (2002) 45-69.

[6] A. Belousov, M. Belousova, B. Voight, Multiple edifice failures, debris avalanches and associated eruptions in the Holocene history of Shiveluch volcano, Kamchatka, Russia, Bull. Volcanol. 61 (1999) 324-342.

[7] O.E. Melnik, R.S.J. Sparks, Non-linear dynamics of lava dome extrusion, Nature 402 (1999) 37-41.

[8] K. Cashman, J. Blundy, Degassing and crystallization of ascending andesite and dacite, Philos. Trans. R. Soc. Lond. A 358 (2000) 1487-1513.

[9] S. Nakada, Y. Motomura, Petrology of the 1991-1995 eruption at Unzen effusion pulsation and groundmass crystallization, J. Volcanol. Geotherm. Res. 89 (1999) 173-196.

[10] R.S.J. Sparks, M.D. Murphy, A.-M. Lejenue, R.B. Waths, J. Barclay, S.R. Young, Control on the emplacement of the andesite lava dome of the Soufriere Hills volcano by degassing-induced crystallization, Terra Nova 12 (2000) 14-20.

[11] B.D. Marsh, On crystallinity, probability of occurrence and rheology of lava and magma, Contrib. Mineral. Petrol. 78 (1981) 85-98.

[12] A.M. Lejeune, P. Richet, Rheology of crystal-bearing melts: an experimental study at high viscosities, J. Geophys. Res. 100 (1995) 4215-4229.

[13] J.A. Whitehead, K.R. Helfrich, Instability of flow with temperature-dependent viscosity: a model of magma dynamics, J. Geophys. Res. 96 (1991) 4145-4155.

[14] B.D. Marsh, On the interpretation of crystal size distributions in magmatic systems, J. Petrol. 39 (1998) 553-599.

[15] G.D. Byrne, A.C. Hindmarsh, A polyalgorithm for the numerical solution of ordinary differential equations, ACM Trans. Math. Softw. 1 (1975) 71-96.

[16] Y.B. Slezin, Dispersion regime dynamics in volcanic eruptions. 2. Flow rate instability condition and nature of catastrophic explosive eruptions, Vulkanol. Seismol. 1 (1984) 23-35.

[17] A.W. Woods, T. Koyaguchi, Transitions between explosive and effusive volcanic eruptions, Nature 370 (1994) 641-644.

[18] O.E. Melnik, Dynamics of two-phase conduit flow of high-viscosity gas-saturated magma: Large variations of sustained explosive eruption intensity, Bull. Volcanol. 62 (2000) 153-170.

[19] C. Jaupart, C. Allegre, Gas content, eruption rate and instabilities of eruption in silicic volcanoes, Earth Planet. Sci. Lett. 102 (1991) 413-429.

[20] M.V. Stasiuk, C. Jaupart, R.S.J. Sparks, On the variations of flow rate in non-explosive lava eruptions, Earth Planet. Sci. Lett. 114 (1993) 505-516.

[21] M.J. Rutherford, P.M. Hill, Magma ascent rates from amphibole breakdown: an experimental study applied to the 1980-1986 Mount St Helens eruptions, J. Geophys. Res. 98 (1993) 19667-19685.

[22] J.S. Pallister, R.P. Hoblitt, D.R. Crandell, D.R. Mullineaux, Mount St Helens a decade after the 1980 eruptions - magmatic models, chemical-cycles, and a revised hazards assessment, Bull. Volcanol. 54 (1992) 126-146.

[23] K.U. Hess, D.B. Dingwell, Viscosities of hydrous leucogranite melts: a non-Arrhenian model, Am. Mineral. 81 (1996) 1297-1300.

[24] A.J.L. Harris, L.P. Flynn, W.I. Rose, Temporal trends in Lava Dome Extrusion at Santiaguito 1922-2000, J. Volcanol. Geotherm. Res. (2002) in press.

[25] S.N. Williams, S. Self, The October 1902 plinian eruptions of Santa Maria volcano, Guatemala, J. Volcanol. Geotherm. Res. 16 (1983) 33-56.

[26] M.V. Stasiuk, C. Jaupart, Lava flow shapes and dimensions as reflections of magma system conditions, J. Volcanol. Geotherm. Res. 78 (1997) 31-50.

[27] A.W. Woods, T. Koyaguchi, Transitions between explosive and effusive eruptions of silicic magmas, Nature 370 (1994) 641-645. 